\title{
Bacterioferritin: a key iron storage modulator that affects strain growth and butenyl-spinosyn biosynthesis in Saccharopolyspora pogona
}

Jianli Tang ${ }^{\dagger}$, Zirong Zhu ${ }^{\dagger}$, Haocheng He, Zhudong Liu, Ziyuan Xia, Jianming Chen, Jinjuan Hu, Li Cao, Jie Rang ${ }^{*}$, Ling Shuai, Yang Liu, Yunjun Sun, Xuezhi Ding, Shengbiao Hu and Liqiu Xia* (1)

\begin{abstract}
Background: Butenyl-spinosyn, produced by Saccharopolyspora pogona, is a promising biopesticide due to excellent insecticidal activity and broad pesticidal spectrum. Bacterioferritin ( $\mathrm{Bfr}$, encoded by bfr) regulates the storage and utilization of iron, which is essential for the growth and metabolism of microorganisms. However, the effect of Bfr on the growth and butenyl-spinosyn biosynthesis in S. pogona has not been explored.

Results: Here, we found that the storage of intracellular iron influenced butenyl-spinosyn biosynthesis and the stress resistance of S. pogona, which was regulated by Bfr. The overexpression of bfr increased the production of butenylspinosyn by 3.14-fold and enhanced the tolerance of S. pogona to iron toxicity and oxidative damage, while the knockout of bfr had the opposite effects. Based on the quantitative proteomics analysis and experimental verification, the inner mechanism of these phenomena was explored. Overexpression of bfr enhanced the iron storage capacity of the strain, which activated polyketide synthase genes and enhanced the supply of acyl-CoA precursors to improve butenyl-spinosyn biosynthesis. In addition, it induced the oxidative stress response to improve the stress resistance of S. pogona.
\end{abstract}

Conclusion: Our work reveals the role of Bfr in increasing the yield of butenyl-spinosyn and enhancing the stress resistance of S. pogona, and provides insights into its enhancement on secondary metabolism, which provides a reference for optimizing the production of secondary metabolites in actinomycetes.

Keywords: Saccharopolyspora pogona, Bacterioferritin, Butenyl-spinosyn, Quantitative proteomics, Secondary metabolism

\section{Background}

Soil microbial actinomycetes can produce a variety of secondary metabolites, many of which are biologically active natural products that have important application value in industry, medicine and agriculture, and are valuable resources for human development and utilization

\footnotetext{
*Correspondence: rang0214@hunnu.edu.cn; xialq@hunnu.edu.cn

${ }^{\dagger} J$ ianli Tang and Zirong Zhu contributed equally to this study

Hunan Provincial Key Laboratory for Microbial Molecular Biology, State Key Laboratory of Developmental Biology of Freshwater Fish, College

of Life Science, Hunan Normal University, Changsha 410081, China
}

[1-3]. Butenyl-spinosyn, a secondary metabolite produced by the aerobic fermentation of the soil actinomycete Saccharopolyspora pogona, is a spinosyn structural analog [4], that effectively kills pests by paralyzing the nervous system of insects [5].This unique insecticidal mechanism makes it powerful in the insecticidal spectrum, harmless to humans and animals, environmentally friendly, safe as a biological pesticide and as a chemical pesticide, giving it broad application prospects in agriculture $[6,7]$.

The side chain groups of butenyl-spinosyn are easily modified to generate many derivatives, and more than original author(s) and the source, provide a link to the Creative Commons licence, and indicate if changes were made. The images or other third party material in this article are included in the article's Creative Commons licence, unless indicated otherwise in a credit line to the material. If material is not included in the article's Creative Commons licence and your intended use is not permitted by statutory regulation or exceeds the permitted use, you will need to obtain permission directly from the copyright holder. To view a copy of this licence, visit http://creativecommons.org/licenses/by/4.0/. The Creative Commons Public Domain Dedication waiver (http://creativeco mmons.org/publicdomain/zero/1.0/) applies to the data made available in this article, unless otherwise stated in a credit line to the data. 
30 derivatives have been isolated and identified so far [4]. However, the low yield of wild-type butenyl-spinosyn under natural conditions hinders its industrial production and application $[8,9]$. Initially, culture media optimization, physical or chemical mutagenesis, and gene rearrangement have been used to explore the potential productivity of secondary metabolites from Streptomyces $[10,11]$. With the development of genetic manipulation technology and research on biosynthetic pathways and metabolic regulation networks, the use of genetic engineering, metabolic engineering, and construction of chassis cell heterologous biosynthesis has made strain modification easier and more efficient $[12,13]$.

Preliminary studies have been conducted on the metabolic pathways and regulatory mechanisms of butenyl-spinosyn biosynthesis [14]. Genome sequencing comparison has revealed that the PKS gene in the butenyl-spinosyn biosynthetic gene cluster is very similar to spinosyn (91\%-94\%), and there are many similarities in their biosynthetic and metabolic pathways [8].The main difference is that of the 5 functional domains encoded by busA in the butenyl-spinosyn gene cluster, a butenyl group replaces the ethyl group at position C21 $[15,16]$. Short-chain acyl-CoAs, such as acetyl-CoA, malonylCoA, methylmalonyl-CoA and propanoyl-CoA, are important precursors for the synthesis of many polyketide secondary metabolites, including butenyl-spinosyn $[15,17]$. Previous studies have shown that the tet $R$ family of transcriptional regulators play an important regulatory role in the growth and biosynthesis of butenyl-spinosyn in S. pogona $[18,19]$. Analysis of metabolic pathways, targeted overexpression of key modules in the biosynthetic process or deletion of competitive PKS gene clusters can significantly increase the production of butenyl-spinosyn [8]. Song, et al used RedEx technology to replace different modules based on the gene cluster of spinosyn and performed heterologous expression in Streptomyces albicans, successfully synthesizing butenyl-spinosyn [20]. In addition, the concentrations of inorganic salts, such as phosphate and iron salt necessary for microorganisms in culture medium affected the growth and secondary metabolism in Streptomyces [21-23].

Iron is a trace element necessary for the growth and development of microorganisms, and it participates in various life activities such as oxygen transport, DNA synthesis, and catalytic protease reactions in cells [24, 25]. However, the extremely low solubility of $\mathrm{Fe}^{3+}\left(\sim 10^{-18} \mathrm{M}\right)$ at normal physiological $\mathrm{pH}$ limits its utilization in biological cells, and excessive $\mathrm{Fe}^{2+}$ will catalyze the production of a large number of reactive oxygen free radicals and cause oxidative damage to cells [26]. Therefore, microorganisms have evolved a way to obtain and store iron through bacterioferritin (Bfr), so that the iron content in cells is strictly maintained within an appropriate range $[27,28]$. Bfr can store extracellular free iron in the form of $\mathrm{Fe}^{3+}$, for release in the form of $\mathrm{Fe}^{2+}$ when required by cell biological metabolic activities [29]. Additionally, Bfr can isolate iron in the cavity when the iron concentration is very high to avoid oxidation by hydrogen peroxide, superoxide, ozone, etc., and assist cells enhancing resistance to oxidative stress [30]. Bfr plays an important role in the growth and development of a variety of bacteria, such as nodulation and nitrogen fixation in Azorhizobium caulinodans [31], and could also improve the virulence of Agrobacterium tumefaciens by regulating iron homeostasis and oxidative stress [32]. Pathogenesis and drug resistance are also closely related to Bfr in $\mathrm{Myco-}$ bacterium tuberculosis [33]. In addition, inhibiting the BfrB:Bfd interaction in Pseudomonas aeruginosa led to the accumulation of $\mathrm{Fe}^{3+}$ and the lack of $\mathrm{Fe}^{2+}$ in the cytoplasm [34]. Although the functions of Bfr in other bacteria are clear, there are few reports about the effects of $\mathrm{Bfr}$ on the growth, development and biosynthesis of secondary metabolites in actinomycetes.

In this study, we found that the concentration of $\mathrm{Fe}^{2+}$ in the medium is closely related to the growth and biosynthesis of butenyl-spinosyn in S. pogona. Manipulating $b f r$ led to a very large difference in the phenotype of the strains and the production of butenyl-spinosyn with altered iron storage capacity. Quantitative proteomics and experimental verification were implemented to gain insight into the metabolic mechanisms of these phenomena. We proposed a working model to explain the effect of Bfr on growth and butenyl-spinosyn biosynthesis in $S$. pogona.

\section{Results}

Iron affects the growth and biosynthesis of butenyl-spinosyn in S. pogona

To explore the effects of iron on growth and secondary metabolism in S. pogona, different concentrations of $\mathrm{FeSO}_{4}(0 \mu \mathrm{M}, 20 \mu \mathrm{M}, 100 \mu \mathrm{M}$ and $5 \mathrm{mM})$ were added into SFM, the strain density of $S$. pogona and butenyl-spinosyn production were subsequently measured. It clearly showed that the strain density elevated with increasing iron concentration within a suitable range $(0-100 \mu \mathrm{M})$, but excessive iron $(5 \mathrm{mM})$ significantly inhibited the growth of the strain and caused the stable growth period to advance and enter the decline phase prematurely (Fig. 1a).

High performance liquid chromatography (HPLC) was used to detect the $S$. pogona fermentation broth extract samples to explore the production of butenyl-spinosyn in different iron concentration (Fig. 1b). There was a significant difference in the HPLC peak at approximately 13 min, which was confirmed to be butenyl-spinosyn by 


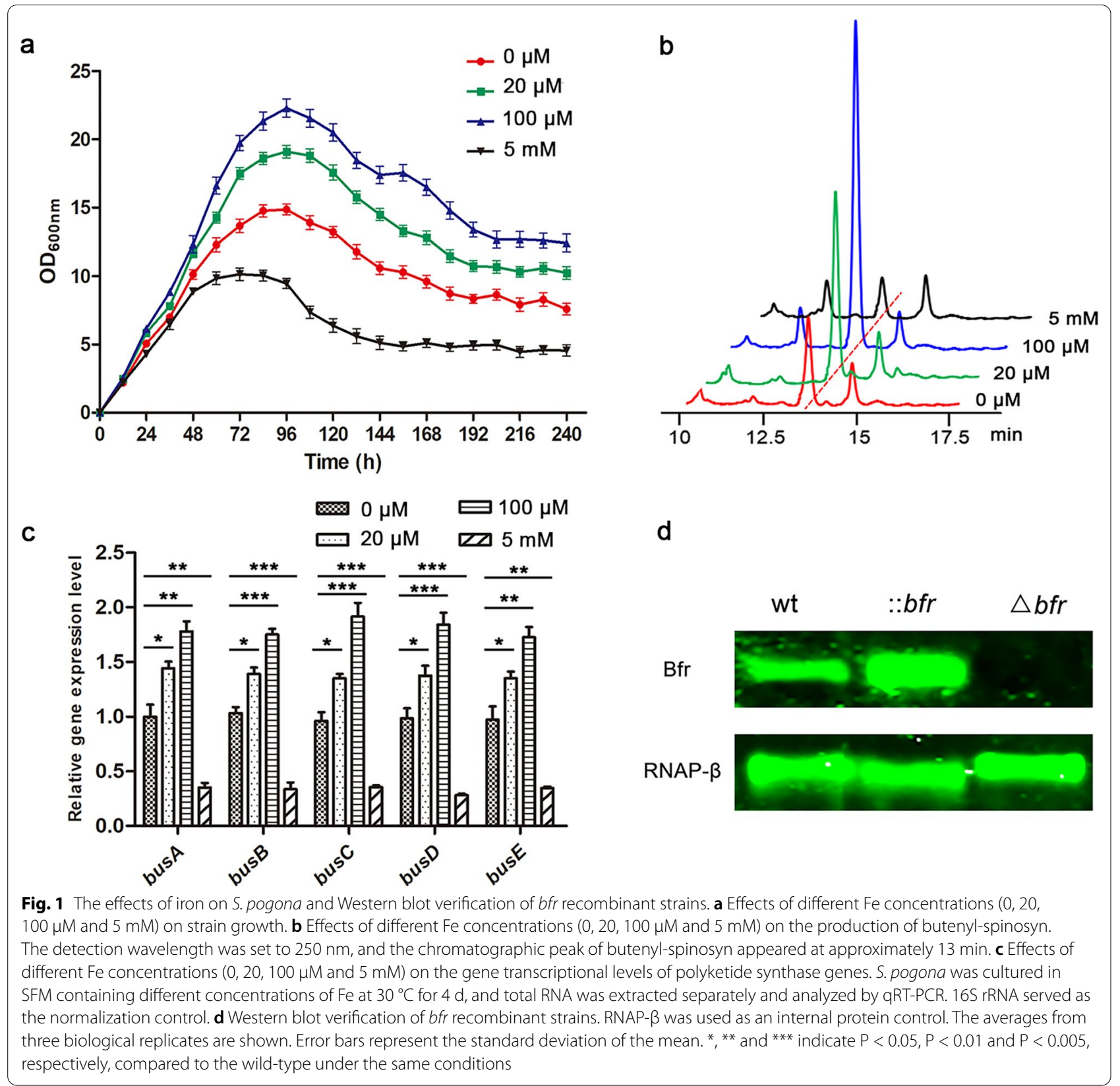

LC-MS/MS analysis (Additional file 1: Figure S1). The yield of butenyl-spinosyn reached the maximum when the iron concentration was $100 \mu \mathrm{M}$, and the lowest when the iron concentration was $5 \mathrm{mM}$. The qRT-PCR checking of the transcriptional levels of polyketide synthase genes (busA, busB, busC, busD, busE) , which control the synthesis of butenyl-spinosyn carbon skeleton [15], was consistent with that of HPLC analysis (Fig. 1c). The results showed that the biosynthesis of butenyl-spinosyn was closely related to the iron concentration in the medium, and an appropriate iron concentration was beneficial for the synthesis of butenyl-spinosyn. The above results strongly suggested that iron played an important role in the growth, development and biosynthesis of butenyl-spinosyn in S. pogona.

An orf (orf 11096-6924, termed as $b f r$ thereafter) which encodes an analogue of bacterioferritin (Bfr) was found by analyzing the whole-genome of $S$. pogona. Phylogenetic tree analysis showed that $\mathrm{Bfr}$ is widespread in actinomycetes (Additional file 1: Figure S2). In order to explore whether $b f r$ affects the iron storage, growth and biosynthesis of butenyl-spinosyn in S. pogona, $b f r$ 
knockout strain $(\Delta b f r)$ and overexpression strain (::bfr) were subsequently constructed (Additional file 1: Figure S3) and verified by using PCR, qRT-PCR and Western blot (Additional file 1: Figure S4, Fig. 1d).

\section{bfr affects the iron storage capacity and growth of S. pogona}

Taking into account the influence of different iron concentrations on the growth of $S$. pogona (Fig. 1a), the strain density in SFM containing $100 \mu \mathrm{M} \mathrm{FeSO}{ }_{4}$ were measured (Fig. 2a). Compared to the wild-type, ::bfr was more vigorous, having a longer stable period and the largest strain density, while the growth of $\Delta b f r$ was significantly inhibited, and the stable period was advanced, which was similar to the original strain under the inhibition of excess iron (5 mM) (Fig. 1a). Scanning electron microscopy (SEM) was used to observe morphology of $S$. pogona (Fig. 2b). The wild-type and
$:: b f r$ strains had normal growth morphology, while the hyphae of $\Delta b f r$ were short and broken, indicating that $\Delta b f r$ had entered the decline period prematurely, which was consistent with the growth curve trend. These results indicated that $b f r$ could affect the iron storage potential of S. pogona.

Subsequently, the intracellular iron content was measured to verify the effects of Bfr on the iron storage capacity of $S$. pogona (Fig. 2c). The intracellular iron concentration of ::bfr was $3.42 \pm 0.24 \mu \mathrm{mol} / \mathrm{g}$, which was significantly higher than that of the wild-type $(1.50 \pm 0.11$ $\mu \mathrm{mol} / \mathrm{g})$, while the intracellular iron concentration of $\Delta b f r$ was only $0.42 \pm 0.04 \mu \mathrm{mol} / \mathrm{g}$. The results showed that the iron storage capacity of ::bfr was significantly stronger than that of $\Delta b f r$ and the wild-type strains, confirming that the difference in iron storage capacity caused by the mutation of $b f r$ was an important reason for the difference in the growth of $S$. pogona.

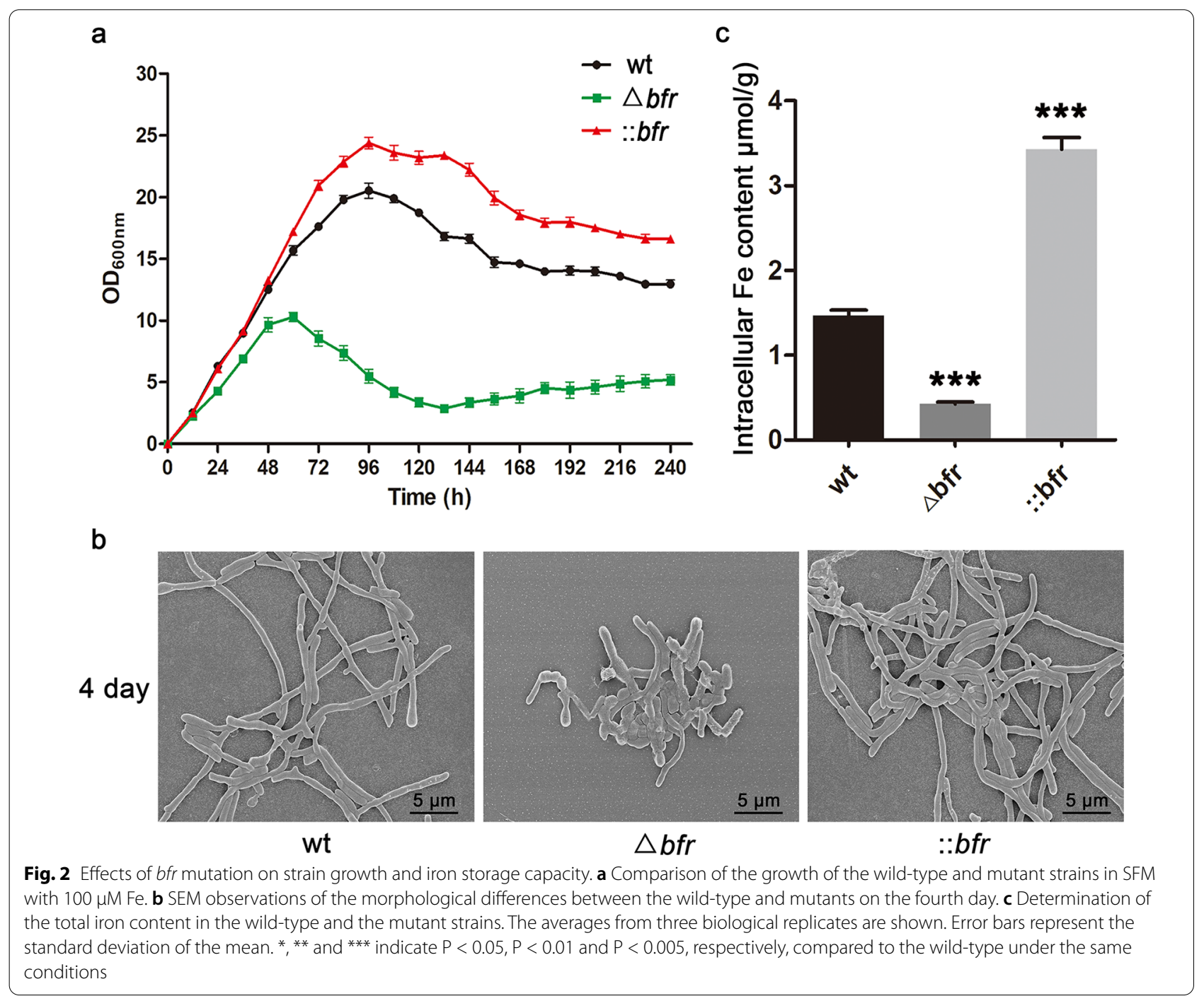




\section{Overexpression of bfr enhances iron toxicity tolerance and delays sporulation}

To explore the role of Bfr in strains resisting high concentrations of iron, we added different concentration gradients of $\mathrm{FeSO}_{4}(0,100,500,1000,5000$, and 10,000 $\mu \mathrm{M})$ to the CSM solid medium followed by cultivation for 6 days, then monitor the growth of S. pogona (Fig. 3a). Without supplemental of $\mathrm{FeSO}_{4}$ in $\mathrm{CSM}$, the timing of sporulation was advanced and the yield of spores was elevated in $\Delta b f r$ compared with the wild-type and ::bfr. The qRTPCR results showed that the transcription levels of the sporulation-related genes (sigF, ssgA, whiA, whiB) in $\Delta b f r$ were significantly higher than those in the wild-type strain, which increased by 1.68 -fold, 1.58-fold, 2.04-fold and 1.68 -fold, respectively (Fig. $3 \mathrm{~b}$ ). These results indicated that the deletion of $b f r$ promoted the expression of sporulation genes and improved sporulation ability.

The colony surface area statistics on CSM with 0 and $100 \mu \mathrm{M} \mathrm{FeSO}_{4}$ showed that the growth rate of $\Delta b f r$ colonies was significantly lower than that of the wild-type and $:: b f r$ colonies, which was consistent with the results of the growth curve in SFM liquid culture (Fig. 3c). Notably, the colony surface area of the wild-type and ::bfr strains with $100 \mu \mathrm{M} \mathrm{FeSO}{ }_{4}$ was significantly larger than that without $\mathrm{FeSO}_{4}$, while the result for $\Delta b f r$ was the opposite, further showing that the growth of $\Delta b f r$ was highly sensitive to the toxicity of $\mathrm{Fe}^{2+}$. As the concentration of $\mathrm{FeSO}_{4}$ continued to increase, the growth of the three strains was gradually inhibited to varying degrees. The $\Delta b f r$ could hardly grow when the concentration of $\mathrm{FeSO}_{4}$ was above $1000 \mu \mathrm{M}$, while the wild-type strain could grow and with the sporulation ahead of schedule, which may be due to feedback from the high iron concentration stress. The wild-type strain could hardly grow at a concentration of 5000 $\mu \mathrm{M} \mathrm{FeSO}$, while ::bfr could, although compared with the strain without $\mathrm{FeSO}_{4}$, the surface area of the ::bfr colonies was slightly reduced at the highest iron level, and spores were hardly produced early. These results suggested that the overexpression of $b f r$ enhanced the

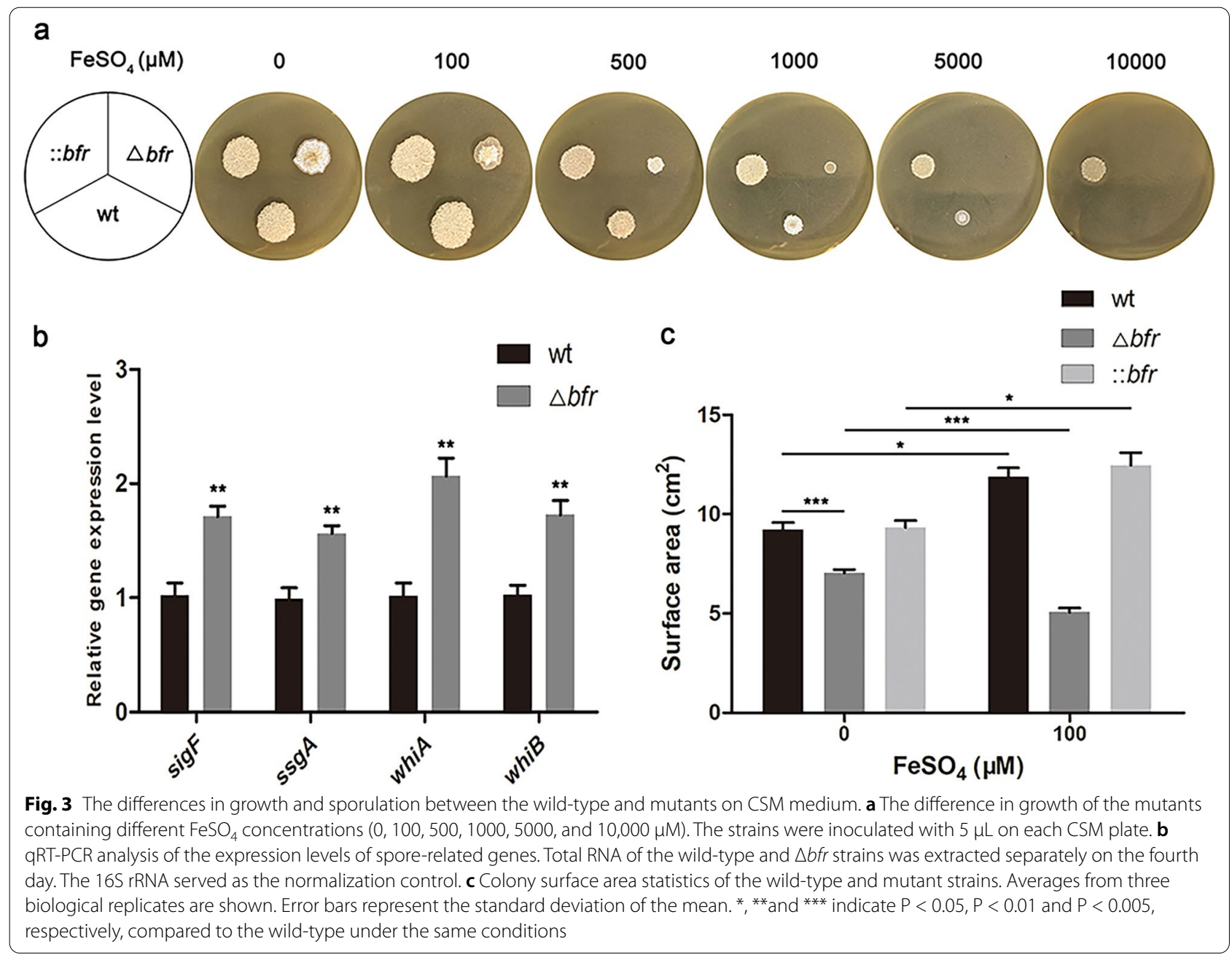


tolerance to iron toxicity and hindered sporulation in S. pogona.

\section{Effects of bfr on butenyl-spinosyn biosynthesis and insecticidal toxicity}

The phenotypic differences between the wild-type and mutants were suggestive of whether there were significant differences in butenyl-spinosyn. The HPLC analysis showed that overexpression of $b f r$ greatly increased the yield of butenyl-spinosyn $(71.22 \pm 7.89 \mathrm{mg} / \mathrm{L})$, which was 3.14-fold higher than that of the wild-type $(22.65 \pm 0.95$ $\mathrm{mg} / \mathrm{L})$. The yield of butenyl-spinosyn after knocking out $b f r$ was significantly reduced $(6.43 \pm 0.56 \mathrm{mg} / \mathrm{L})$ and only 0.28 -fold that of the wild-type (Fig. $4 \mathrm{a}$, Additional file 1: Figure S6).

The difference of butenyl-spinosyn yield between the wild-type and mutants was visually presented in the insecticidal activity against Helicoverpa armigera (Fig. 4b, c). The $\Delta b f r$ mutant showed a slow decline in survival, while the ::bfr mutant caused remarkably rapid death, with the lethal time $\left(\mathrm{LT}_{50}\right)$ advancing by 2.111 days (Additional file 1: Table S3), and the surviving insects refused to feed and their growth slowed down.

To explore the effect of $b f r$ on butenyl-spinosyn biosynthesis, the expression levels of polyketide synthase genes from bus gene cluster were detected by qRT-PCR. The data showed that the expression levels of these genes were upregulated to varying degrees in $:: b f r$, while that were significantly suppressed in $\Delta b f r$ (Fig. 4d). These results confirmed that $b f r$ positively affect the production of butenyl-spinosyn and insecticidal activity of the fermentation broth supernatant by strengthening polyketide synthases in S. pogona.

\section{Quantitative proteomic analysis of S. pogona and the mutant strains}

To further reveal the internal factors underlying the large differences between wild-type and mutant strains, a quantitative proteomics analysis was performed using TMT labeling. A total of 5013 proteins were identified in the wild-type and mutant strains, 428 proteins were upregulated and 536 proteins were downregulated in $:: b f r$ and 149 proteins were upregulated and 263 proteins were downregulated in $\Delta b f r$ (Additional file 1: Figure S7). Based on quantitative proteomics data, a metabolic network pathway diagram was constructed by KEGG analysis (Fig. 5; Additional file 2: Table S4; Additional file 3: Table S5). Compared with the wild-type, the more differentially expressed proteins (DEPs) in the $b f r$ mutants were those involved in central carbon metabolism and oxidative phosphorylation pathways.
Increased acyl-CoA metabolic flux provides more precursor substances for the biosynthesis of butenyl-spinosyn

Acetyl-CoA, methylmalonyl-CoA, malonyl-CoA and other short-chain acyl-CoAs are important sources of precursor substances for primary metabolism and the biosynthesis of butene-spinosyn. The expression levels of rate-limiting enzymes involved in glycolysis (such as fbaA, gpmA, eno, korA, and korB), fructose and mannose metabolism (such as $s c r K$, fruK and $f b a B$ ), fatty acid degradation (such as fadD, fadJ, paaF, fadA, and atoB), amino acid degradation (such as $b k d A$, pdhD, paaF, fadJ, and $A L D H)$, and benzoate degradation (such as fadA, fadJ, and paaF) were all significantly upregulated in ::bfr compared to the wild-type strain, which promoted the synthesis of acylCoA precursors. Conversely, the expression levels of enzymes involved in the pentose phosphate pathway (such as $\operatorname{dev} B, t k t A$, and rpiA) and the key rate-limiting enzyme pyruvate carboxylase $(p y c)$ that catalyzes the production of oxaloacetate from pyruvate to the TCA cycle were all significantly downregulated, reducing the loss of acetyl-CoA to other pathways. Normal growth of ::bfr was ensured due to the upregulation of the key enzymes (such as korA, sucC, sucD, and $f u m A)$ in the TCA cycle. Moreover, the expression levels of related enzymes involved in the oxidative phosphorylation pathway were significantly upregulated, including the NADH-quinone oxidoreductase subunit (nuoN, nuoM), polyphosphate kinase (ppk) and F-type $\mathrm{H}^{+}$-transporting ATPase (ATPF1A, ATPF1B, ATPF1G), providing sufficient energy for cell metabolism $[35,36]$. In addition, the four polyketide synthases (BusA, BusB, BusC, BusD) detected were also upregulated to varying degrees in $:: b f r$, which was consistent with the results of qRT-PCR (Additional file 1: Figure S8).

The above analysis showed that $b f r$ has a positive effect on the expression of enzymes related to central carbon metabolism. The advantage of ::bfr in glucose utilization efficiency was confirmed by monitoring the glucose consumption during the fermentation of S. pogona (Fig. 6a). Therefore, we speculated that the overexpression of $b f r$ could promote the synthesis and accumulation of acetyl-CoA, malonyl-CoA, and methylmalonyl-CoA, providing sufficient precursors for butenyl-spinosyn biosynthesis. The intracellular content of these precursors at different time points was analyzed and the results showed that their concentrations were significantly higher in ::bfr than that in the wild-type, confirming our hypothesis (Fig. 6b, c, d). 


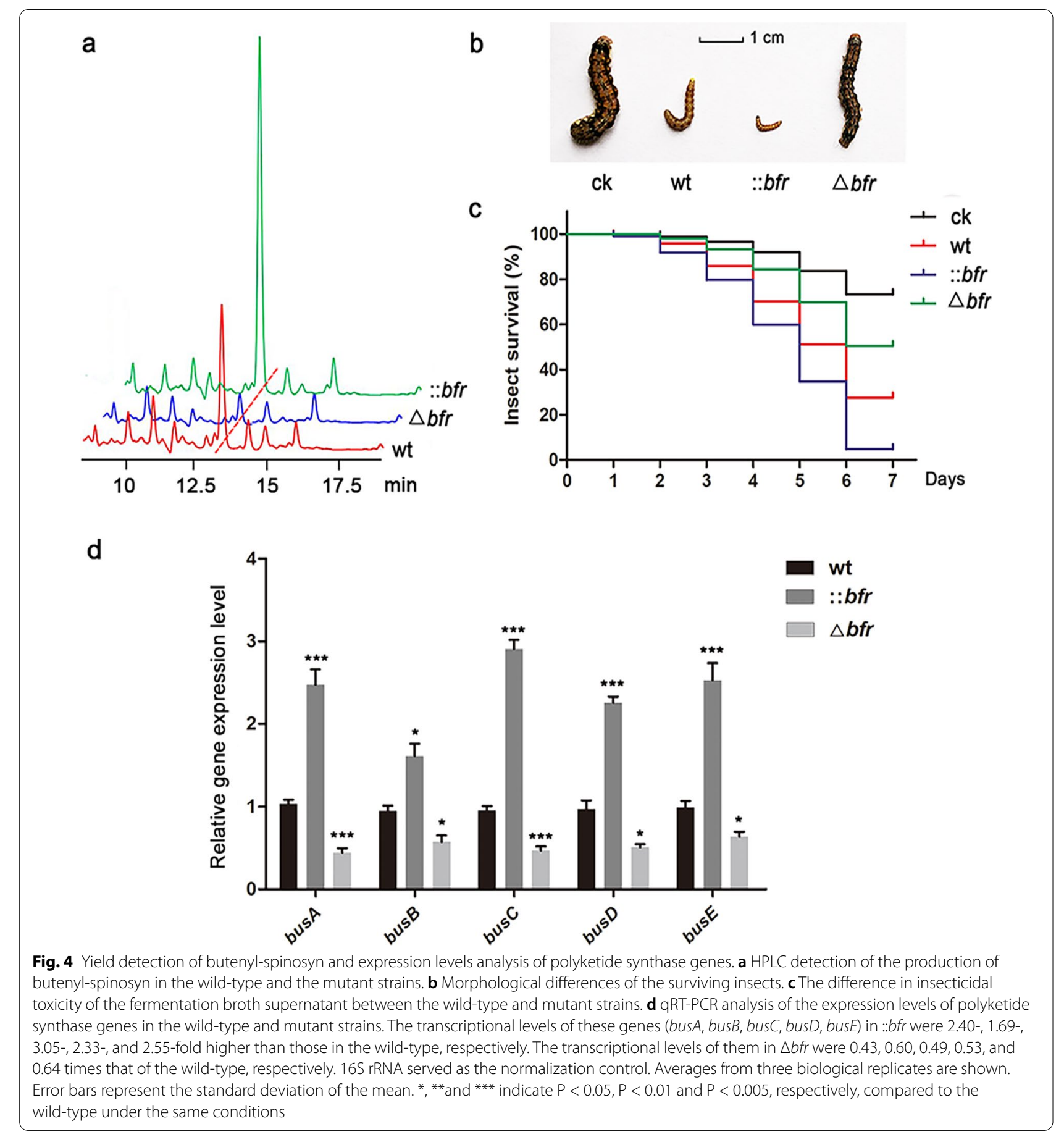

\section{Oxidative stress response enhances the stress resistance of ::bfr}

The storage and utilization of iron by Bfr in cells generates large amounts of reactive oxygen species (ROS), including superoxide, $\mathrm{H}_{2} \mathrm{O}_{2}$ and hydroxyl radical, which can result to oxidative damage of cells if not scavenged in time [27]. To uncover the reasons for the differences in iron storage and tolerance in $b f r$ mutant and wild type strains, we analyzed DEPs associated with iron homeostasis and oxidative stress (Table 1; Additional file 1: Figure S9).

As expected, the expression level of Bfr was significantly higher in ::bfr than in the wild-type, and it failed to be detected in $\Delta b f r$. In addition, the expression level of 


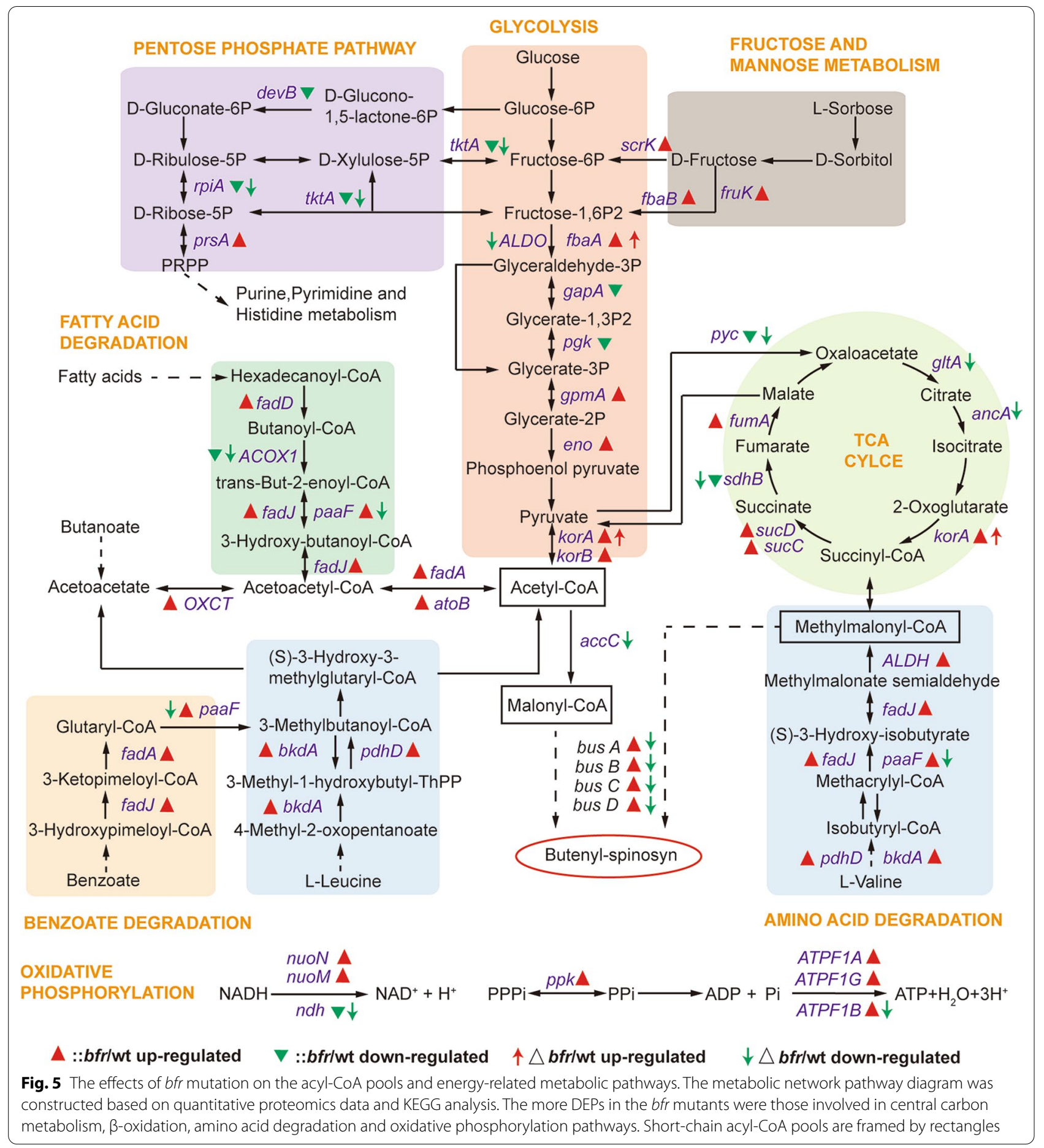

ferredoxin, which is involved in cellular iron binding and electron transfer in redox reactions [37], was also significantly higher in ::bfr. Notably, the expression levels of thioredoxin reductase ( $\operatorname{TrxB})$, catalase-peroxidase (KatG) and superoxide dismutase (SOD), which are involved in oxidative stress response [38-40], were all significantly increased in ::bfr, suggesting a possible difference in antioxidant capacity between the mutant and wild-type strains (Table 1). Therefore, the total antioxidant capacity (T-AOC) was detected in different strain, and the result showed that the T-AOC of ::bfr was stronger than that of the wild-type, whereas it decreased significantly after 

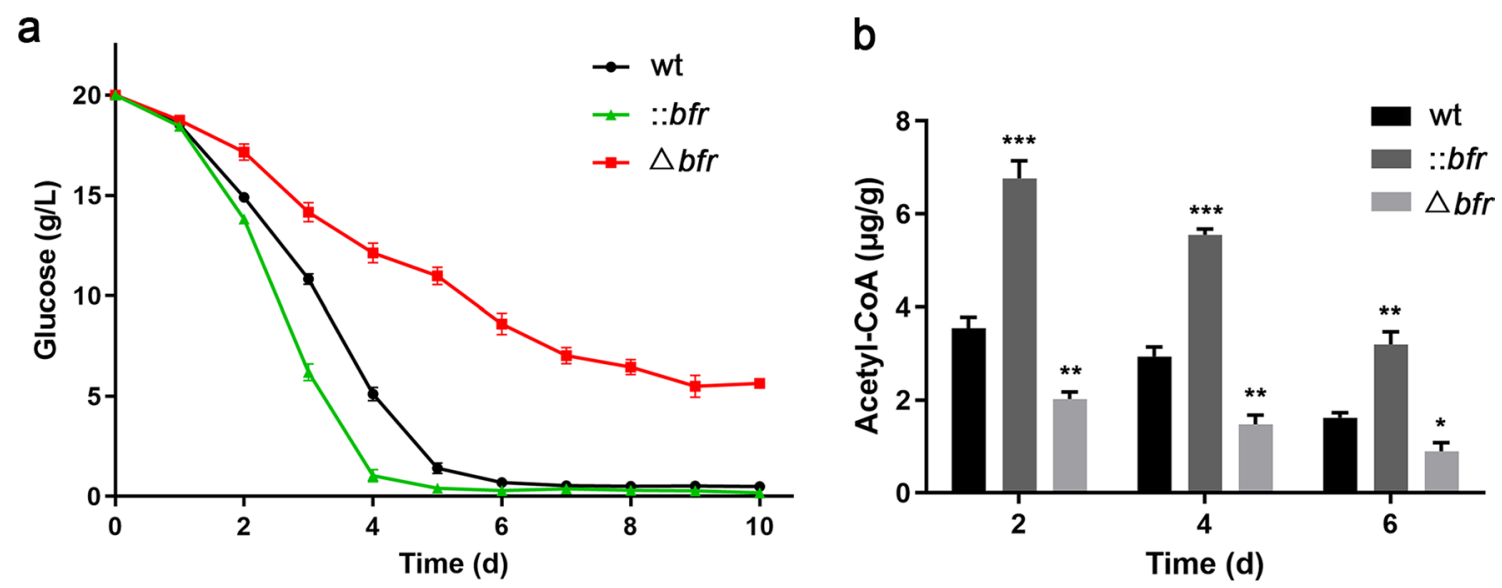

C

d
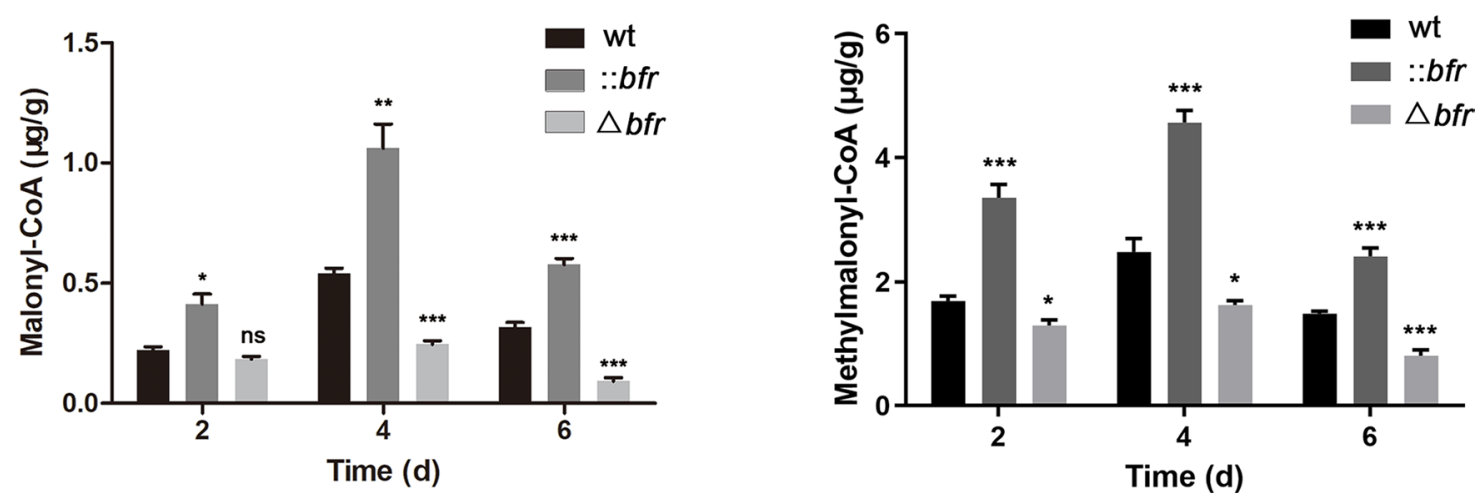

Fig. 6 The analysis of glucose consumption and acyl-CoA precursors accumulation. a Comparison of glucose utilization of the wild-type and mutants in SFM. Compared with the wild-type, :bfr showed stronger glucose utilization capacity, while the glucose utilization of $\triangle b f r$ decreased significantly. $\mathbf{b}$ Determination of acetyl-CoA accumulation in the wild-type and mutants in SFM. c Determination of malonyl-CoA accumulation in the wild-type and mutants in SFM. $\mathbf{d}$ Determination of methylmalonyl-CoA accumulation in the wild-type and mutants in SFM. Averages from three biological replicates are shown. Error bars represent the standard deviation of the mean. ${ }^{*}$, ${ }^{*}$ and ${ }^{* * *}$ indicate $P<0.05, P<0.01$ and $P<0.005$, respectively; ns, no significance, compared to the wild-type under the same conditions

Table 1. Proteins differential expression related to iron homeostasis and oxidative stress in bfr mutant strains

\begin{tabular}{|c|c|c|c|c|c|}
\hline \multirow[t]{2}{*}{ Accession } & \multirow[t]{2}{*}{ Gene } & \multirow[t]{2}{*}{ Protein } & \multirow[t]{2}{*}{ Possible function } & \multicolumn{2}{|c|}{ Fold change } \\
\hline & & & & $:: b f r / w t$ & $\Delta b f r / w t$ \\
\hline A0A2N3XSC8 & A8926_1113 (bfr) & Bacterioferritin & Iron-storage protein & 2.05 & / \\
\hline A0A2N3XUS8 & A8926_2054 (fer) & Ferredoxin & $\begin{array}{l}\text { Iron ion binding, electron transfer } \\
\text { activity }\end{array}$ & 1.52 & 0.61 \\
\hline A0A6H1R6Z6 & $\operatorname{tr} \times B$ & Thioredoxin reductase & Removal of superoxide radicals & 1.49 & 0.55 \\
\hline $\mathrm{A} 0 \mathrm{~A} 6 \mathrm{H} 1 \mathrm{R} 2 \mathrm{G} 0$ & $\operatorname{sodN}$ & Superoxide dismutase & Superoxide dismutase activity & 1.34 & 0.62 \\
\hline A0A6H1RAW2 & katG & Catalase-peroxidase & $\begin{array}{l}\text { Decomposition of hydrogen } \\
\text { peroxide }\end{array}$ & 1.37 & 0.73 \\
\hline
\end{tabular}

deleting $b f r$ (Fig. 7a). Furthermore, experimental data demonstrated that ::bfr was much more tolerant than wild type strain to $\mathrm{H}_{2} \mathrm{O}_{2}$ exposure (Fig. 7b). These results indicated that the overexpression of $b f r$ induce oxidative stress response and thus enhance the strain's resistance to stress. 
a

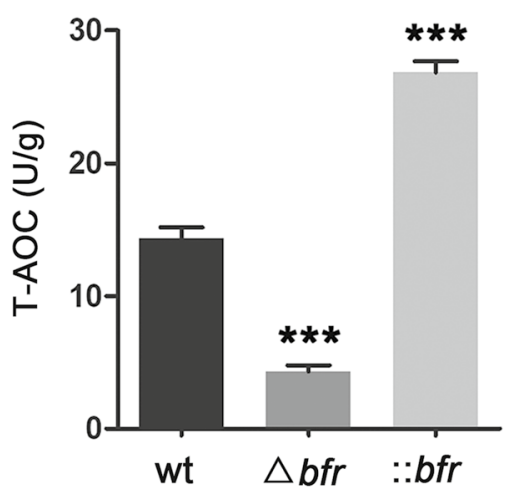

b

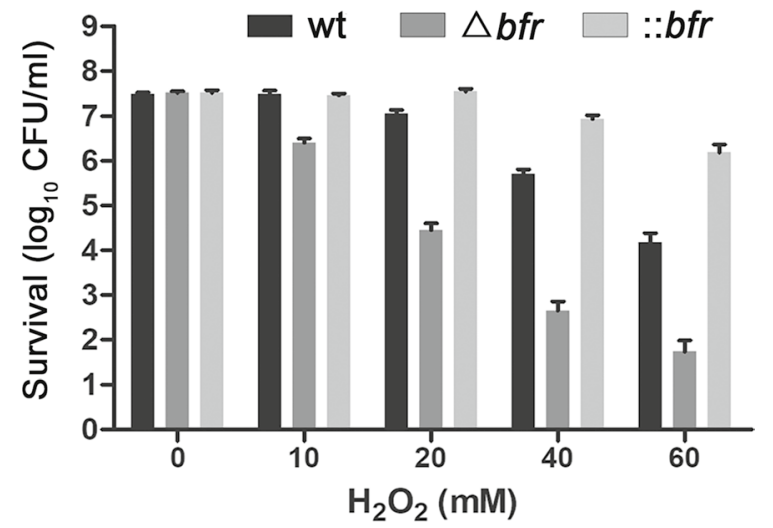

Fig. 7 Antioxidant capacity analysis. a Total antioxidant capacity (T-AOC) detection. : bfr showed stronger antioxidant capacity than the wild-type. b Survival of the wild-type, ::bfr and $\Delta b f r$ strains after exposure to $\mathrm{H}_{2} \mathrm{O}_{2}$. Averages from three biological replicates are shown. Error bars represent the standard deviation of the mean. * **and ${ }^{* * *}$ indicate $\mathrm{P}<0.05, \mathrm{P}<0.01$ and $\mathrm{P}<0.005$, respectively, compared to the wild-type under the same conditions

\section{Discussion}

Metal ions are essential for the growth and metabolism of microorganisms, as they are often important cofactors for various enzymatic reactions in cells [41-43]. For example, iron is widely involved in various key processes on which life activities depend, such as redox reactions, DNA synthesis, and enzyme catalysis [44, 45]. Microbial cells rely on Bfr to maintain the iron concentration in a relatively stable range. However, due to the extremely low solubility of $\mathrm{Fe}^{3+}$ and the toxic ROS produced by $\mathrm{Fe}^{2+}$ during the oxidation process, the use of iron by microorganisms is facing a great challenge [24, 46]. The method of improving secondary metabolites by optimizing only the trace elements added to the fermentation medium has great limitations due to the toxicity of an excess of metal ions to cells. Exploring the mechanism by which iron affect the growth of microorganisms and the synthesis of secondary metabolites is of great significance for increasing the production of valuable secondary metabolites. Therefore, the significant influence of iron on the growth and butenyl- spinosyn biosynthesis of $S$. pogona has aroused our interest (Fig. 1).

Bfr plays an important role in regulating iron storage and utilization in microorganisms [28]. It has also been found to be widely present in actinomycetes (Additional file 1: Figure S2). We effectively improved the ability to store and utilize iron by increasing the expression of the Bfr protein in S. pogona. Phenotypic experiments of the mutant strains showed that ::bfr grows better than the wild-type strain and has stronger anti-iron toxicity. $b f r$ knockout in S. pogona leads to a sharp decline in the ability to store iron, low strain density, extreme sensitivity to iron toxicity, and induction of the expression of spore-related genes, resulting in a large number of spores (Fig. 2, 3). The premature production of spores is often the response of strains to adversity $[47,48]$, indicating that the deletion of $b f r$ reduced the strain's ability to adapt to the environment.

Quantitative proteomics analysis showed that ::bfr strain has the advantages in central carbon metabolism and energy metabolism compared with the wild-type, which provides a better guarantee for growth (Fig. 5). In addition, ferredoxin is a Fe-S protein that mediates electron transfer in a variety of metabolic reactions, aid in iron storage and utilization, and facilitate related metabolism in ::bfr [37]. $\mathrm{Fe}^{2+}$ is oxidized to $\mathrm{Fe}^{3+}$ and stored in $\mathrm{Bfr}$, and then reduced to $\mathrm{Fe}^{2+}$ when needed. Excess iron will aggravate the oxidation-reduction reaction, and a large amount of ROS will be generated in the process [27]. Therefore, the tolerance of strains to iron is closely related to oxidative stress. TrxB can form an antioxidant system with Txr/NADPH to eliminate superoxide [38]. SOD is a kind of antioxidant metal enzymes, which can catalyze the disproportionation of superoxide anion radicals to generate $\mathrm{O}_{2}$ and $\mathrm{H}_{2} \mathrm{O}_{2}$, while KatG can decompose $\mathrm{H}_{2} \mathrm{O}_{2}$ to relieve the threat of oxidative damage to cells [39, 49]. The catalytic activity of these enzymes, such as ferredoxin and SOD, often requires the participation of iron [40]. Therefore, the enhancement of iron storage capacity promoted their expression and activity in ::bfr. Our results suggested that overexpression of $b f r$ leads to an enhanced oxidative stress response, which protects cells from oxidative damage and enhances survival ability of $S$. pogona in an environment with high iron concentration. 
The enhanced stress resistance of high-yielding strains is very beneficial to the stability of large-scale industrial fermentation in complex environments.

The overexpression of $b f r$ also led to a substantial increase in the production of butenyl-spinosyn, which mainly attributed to the activation of polyketide synthase genes and the supply of acyl-CoA flow [50]. The effect of iron on the growth and secondary metabolism of many microorganisms has been revealed by previous studies $[22,23,28]$. In our results, the proper iron concentration not only promoted the growth of $S$. pogona, but also activated the expression of genes related to polyketide chain biosynthesis (Fig. 1). The overexpression of bfr promoted the expression of polyketide synthase genes (Fig. 4d), which may be related to the enhanced iron storage and utilization capacity in S. pogona (Fig. 2b). The DEPs identified from quantitative proteomics mainly focused on central carbon metabolism, $\beta$-oxidation and amino acid degradation (Fig. 5). The overexpression of $b f r$ significantly upregulated the expression of most of the key proteins in these metabolic pathways, while downregulating the key enzymes that control the carbon flux to the pentose phosphate pathway and the TCA cycle. This is conducive to the accumulation of acyl-CoA to provide sufficient precursor materials for the biosynthesis of butenyl-spinosyn (Fig. 6).

These analyses indicated that the overexpression of Bfr caused a substantial increase in the production of butenyl-spinosyns in S. pogona, which may be caused by a combination of multiple factors, including enhanced strain resistance, increased supplying acyl-CoA precursors and activation of polyketide synthase genes. Although these phenomena can be explained and verified by macroscopic and extensive metabolic changes, we still do not know how the enhancement of iron utilization affects these metabolic pathways in detail, especially the effect on the butenyl-spinosyn biosynthetic gene cluster. These in-depth mechanisms need to be further explored. In addition, the quantitative proteomics revealed the unique metabolic advantages of $:: b f r$, which suggests that we may be able to optimize the metabolic pathways to further explore the production potential of ::bfr, thereby increasing the yield of butenyl-spinosyn.

\section{Conclusions}

Collectively, Bfr has an important positive effect on the growth and butenyl-spinosyn biosynthesis in S. pogona through regulating iron homeostasis and oxidative stress response (Fig. 8). This research helps us understand the role of iron in microorganism metabolism, and provides references for improving the production of secondary metabolites and strain resistance in actinomycetes.

\section{Materials and methods}

Plasmids, bacterial strains, media, and growth conditions

The primers, plasmids, and bacterial strains used in this study are listed in Additional file 1: Table S1 and S2. E. coli strains were cultured in Luria-Bertani (LB) broth at $37^{\circ} \mathrm{C}$. Unless otherwise specified, S. pogona (wt), $\Delta b f r$ and ::bfr strains were all cultivated in complete synthetic medium (CSM: trypticase soy broth $45 \mathrm{~g} / \mathrm{L}$, glucose $10 \mathrm{~g} / \mathrm{L}$, yeast extract $9 \mathrm{~g} / \mathrm{L}, \mathrm{MgSO}_{4} 2.2 \mathrm{~g} / \mathrm{L}$ ) with $20 \mathrm{~mL}$ medium per $300 \mathrm{~mL}$ bottle, $30^{\circ} \mathrm{C}, 200 \mathrm{rpm}$ for $48 \mathrm{~h} .2 \mathrm{~mL}$ of activated bacteria suspension was taken out and added to $50 \mathrm{~mL}$ each bottle of synthetic fermentation medium (SFM: glucose $20 \mathrm{~g} / \mathrm{L}$, tryptone $4 \mathrm{~g} / \mathrm{L}$, yeast extract $4 \mathrm{~g} / \mathrm{L}, \mathrm{MgSO}_{4}$ $0.5 \mathrm{~g} / \mathrm{L}, \mathrm{K}_{2} \mathrm{HPO}_{4} 0.5 \mathrm{~g} / \mathrm{L}, \mathrm{KNO}_{3} 1 \mathrm{~g} / \mathrm{L}, \mathrm{FeSO}_{4} \cdot 7 \mathrm{H}_{2} \mathrm{O}$ was added in the corresponding amount as needed, $\mathrm{pH} 7.5$ ), $30{ }^{\circ} \mathrm{C}, 200 \mathrm{rpm}$ for 10 days. The R6 medium (BHI $26 \mathrm{~g} / \mathrm{L}$, sucrose $200 \mathrm{~g} / \mathrm{L}$, dextrin $10 \mathrm{~g} / \mathrm{L}$, casamino acids $1 \mathrm{~g} / \mathrm{L}$, $\mathrm{K}_{2} \mathrm{SO}_{4}, 0.1 \mathrm{~g} / \mathrm{L}, \mathrm{FeSO}_{4} 0.1 \mathrm{~g} / \mathrm{L}, \mathrm{MgSO}_{4} 0.05 \mathrm{~g} / \mathrm{L}, \mathrm{ZnSO}_{4}$ $0.001 \mathrm{~g} / \mathrm{L}, \mathrm{MnCl}_{2} 0.001 \mathrm{~g} / \mathrm{L}$ ) was used for the conjugation transfer of $S$. pogona at $30^{\circ} \mathrm{C} .1 .5 \%(\mathrm{w} / \mathrm{v})$ agar was added to obtain a solid media. Where applicable, Apramycin (Apra, $50 \mu \mathrm{g} / \mathrm{mL}$ ) was added into the above medium for selection.

\section{Construction of plasmids and verification of recombinant strains}

The CRISPR/Cas9 system was used to knock out $b f r$ [51]. The sgRNA guide sequence of $b f r$ was designed by online tool ZIFIT (http://zifit.partners.org) [52], and fusion with upstream and downstream homologous arms of $b f r$ to obtain sgRNA-UHA-DHA. Then the fusion fragment was cloned into pKCcas9dO to obtain pKCcas9dO-sgRNAUHA-DHA by restriction enzyme digestion and ligation (Spe I and Hind III) (Additional file 1: Figure S3a). The pOJ260 was used to overexpress bfr [53]. bfr gene and $\mathrm{kasOp}^{*}$ promoter was amplified and integrated to obtain $k a s O \mathrm{p}^{*}-b f r$. Then the fusion fragment was cloned into pOJ260 to obtain pOJ260-kasOp*-bfr by restriction enzyme digestion and ligation ( $\mathrm{Xba}$ I and Hind III) (Additional file 1: Figure S3b).

The reconstructed plasmids were transformed into $E$. coli $\mathrm{S} 17$ by heat shock, confirmed and introduced into S. pogona by conjugation [54] (Additional file 1: Figure S3c, d). Then, the conjugants with an apramycin-resistant phenotype were selected and confirmed by PCR and qRT-PCR to obtain the recombinant strains (Additional file 1: Figure S4).

\section{Heterologous expression of Bfr and Western blot verification}

The $b f r$ gene fragment was amplified using primers F-bfrl $\mathrm{R}$ - $b f r$ and cloned into the pET28a vector, and introduced into E. coli BL21. Recombinant bacteria were cultured 


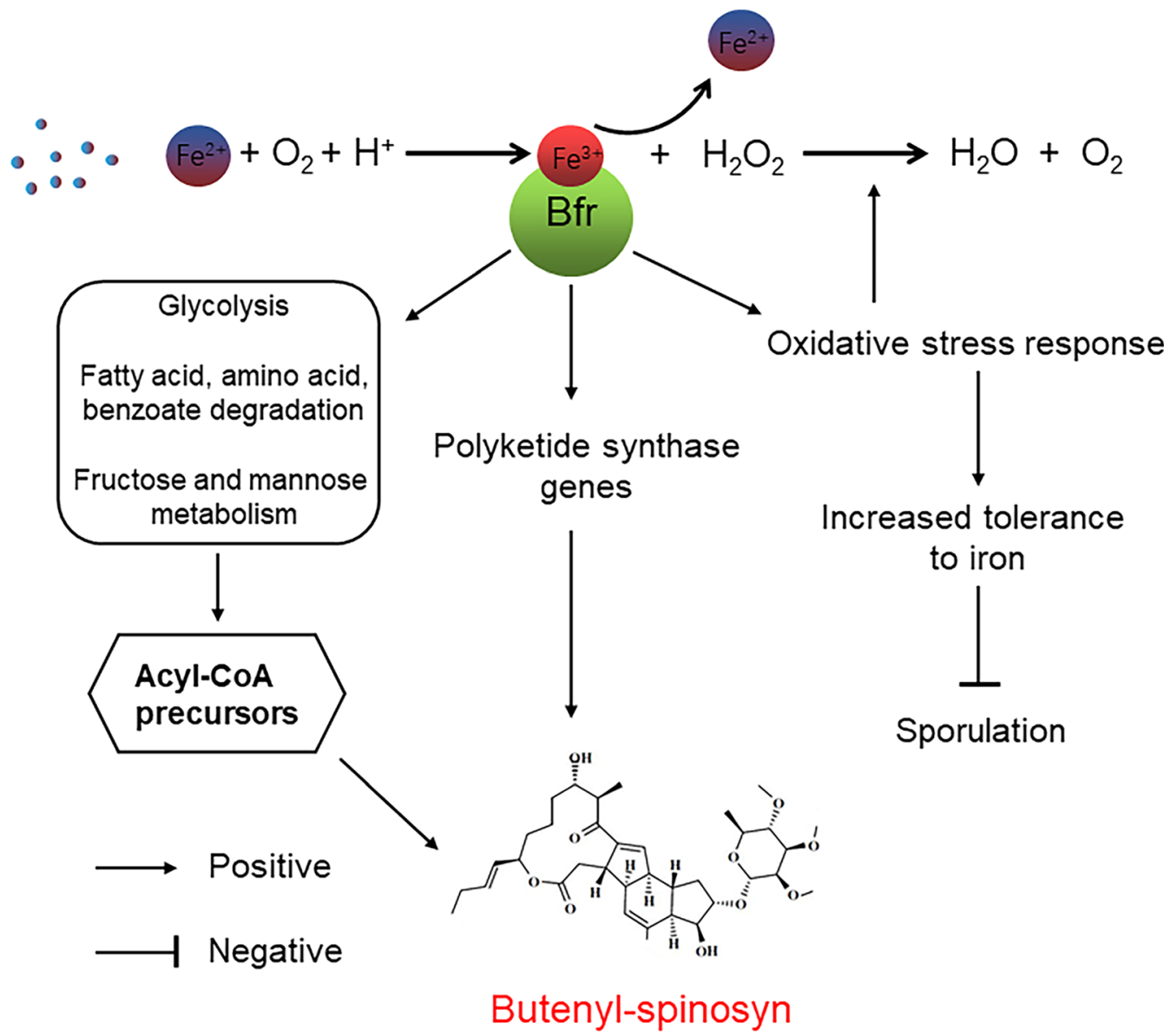

Fig. 8 Working model for the coordinated control of growth metabolism and butenyl-spinosyn biosynthesis through Fe and Bfr in S. pogona. $\mathrm{Fe}^{2+}$ in the environment is absorbed and stored in Bfr in the form of $\mathrm{Fe}^{3+}$, which protects cells from iron toxicity followed by release in the form of $\mathrm{Fe}^{2+}$ for life activities when needed by cells. Overexpression of bfr enhances the ability of strains to store iron, and promotes oxidative stress response to avoid oxidative damage in order to adapt to high iron concentration environments, affects central carbon metabolism and oxidative phosphorylation to synthesize more short-chain acyl-CoA precursors. Together, these factors promote the biosynthesis of butenyl-spinosyn

in LB supplemented with $50 \mu \mathrm{g} / \mathrm{mL}$ kanamycin at $37{ }^{\circ} \mathrm{C}$ for $4 \mathrm{~h}$, and different concentrations of IPTG $(0,25 \mu \mathrm{L})$ were added to induce Bfr protein expression (Additional file 1: Figure S5a). The heterologously expressed protein Bfr was identified by 1D-LC-MS/MS (Additional file 1: Figure S5b), and the anti-Bfr antibody was provided by immunizing BALB/c mice. The Bfr expression level in the wild-type and the mutants was analysed by Western blot [55] (Fig.1d).

\section{Detection of strain density and butenyl-spinosyn}

The wild-type and recombinant strains were cultured in SFM medium for $10 \mathrm{~d}$. Ultraviolet spectrophotometer was used to determine strain density, the wavelength was set to $600 \mathrm{~nm}$. Glass beads were added to the culture medium to avoid the formation of pellets and sediments during the fermentation. The cell suspension was collected every $12 \mathrm{~h}$ and diluted to an appropriate concentration for detection during fermentation. The absorbance value $\left(\mathrm{OD}_{600}\right)$ was recorded and the growth curve was drawn.

High performance liquid chromatography 1290 (HPLC 1290) was used to detect the production of butenyl-spinosyn. $1 \mathrm{~mL}$ of fermentation broth (10th day) was added to an equal volume of ethyl acetate, extracted in a water bath at $65{ }^{\circ} \mathrm{C}$ for $1 \mathrm{~h}$, and centrifuged at $12,000 \mathrm{rpm}$ for $10 \mathrm{~min} .500 \mu \mathrm{L}$ of supernatant was taken out and freeze-dried, then added $50 \mu \mathrm{L}$ of methanol to fully dissolve, centrifuged at $12,000 \mathrm{rpm}$ for $5 \mathrm{~min}$, the supernatant was taken out for detection. The detection conditions were set as the following: column C18 (AQ12S05-1546WT), $4.5 \times 150 \mathrm{~mm}, 4.5 \mu \mathrm{m}$, detection wavelength was set to $250 \mathrm{~nm}$, the sample loading volume was $20 \mu \mathrm{L}$. The elution buffer A: 10\% $(\mathrm{v} / \mathrm{v})$ acetonitrile, buffer B: $90 \%(\mathrm{v} / \mathrm{v})$ acetonitrile. The 
following gradient of buffer B was applied: $0 \mathrm{~min}, 0 \%$; $2 \mathrm{~min}, 0 \%$; $20 \mathrm{~min}, 100 \%$; $22 \mathrm{~min}, 100 \%$; $23 \mathrm{~min}, 0 \%$; $25 \mathrm{~min}, 0 \%$. The flow rate was set to $1 \mathrm{~mL} / \mathrm{min}$. The peaks of interest were collected and concentrated for LC-MS/MS identification (Additional file 1: Figure S1).

\section{Insecticidal activity analysis}

$1 \mathrm{~mL}$ of fermentation broth supernatants of different samples were added to $19 \mathrm{~mL}$ feed (soy flour $120 \mathrm{~g} / \mathrm{L}$, flour $60 \mathrm{~g} / \mathrm{L}$, yeast $20 \mathrm{~g} / \mathrm{L}$, ethyl Paraben $2 \mathrm{~g} / \mathrm{L}$, sorbic acid $1 \mathrm{~g} / \mathrm{L}$, Agar $13 \mathrm{~g} / \mathrm{L}$, vitamin C 20 tablets, vitamin $\mathrm{B}_{2} 10$ tablets) to detect insecticidal activity against $H$. armigera, mixed well and evenly added to 24-well plates, the number of dead insects was recorded every day for 6 days.

\section{Total RNA extraction and qRT-PCR analysis}

Biomass samples of the wild-type and the recombinant strains cultured in SFM for $4 \mathrm{~d}$ were taken out, and total RNA was separated using Total RNA Extractor (Shanghai Sangon Biotech Co., Ltd.) according to the instructions. The RNA concentration and purity were determined by measuring the ratio of $\mathrm{OD}_{260}$ to $\mathrm{OD}_{280}$. The 7500 RealTime PCR system instrument (Applied Biosystems, USA) was used to determine the transcription level of the sample. Prime Script ${ }^{\mathrm{TM}}$ RT Reagent Kit (Takara) were used for DNase treatment and cDNA synthesis according to the instructions. SYB ${ }^{\circledR}$ Permix Ex Tag ${ }^{\text {TM }}$ GC (Takara) was used for qRT-PCR amplification. The primer pairs used in qRT-PCR were listed in Additional file 1: Table S2, and the 16S rRNA gene was used as an internal control to quantify the relative expression level of the samples.

\section{Protein extraction and SDS-PAGE analysis}

Cell suspension of the wild-type and recombinant strains at early stabilization growth phases (4th day) were taken out respectively, and washed 4 times with PBS (prechilled at $4{ }^{\circ} \mathrm{C}, 10 \mathrm{mM}, \mathrm{pH} 7.8$ ) through centrifugation at $10,000 \mathrm{rpm}$ for $10 \mathrm{~min}$ at $4{ }^{\circ} \mathrm{C}$, then the cell pellet was resuspended with $200 \mu \mathrm{L}$ lysozyme $(100 \mathrm{mg} / \mathrm{mL})$, adding $600 \mu \mathrm{L}$ Lysis buffer ( $2 \mathrm{M}$ thiourea , $50 \mathrm{mM}$ Tris- $\mathrm{HCl}$, $75 \mathrm{mM} \mathrm{NaCl}, 8 \mathrm{M}$ urea, 4\% CHAPS, pH 8.0), $2 \mu \mathrm{L}$ EDTA $(1 \mathrm{M})$ and $5 \mu \mathrm{L}$ protease inhibitor in each tube, then ultrasonic fragmentation (JY92-ultrasonic cell grinder, Ningbo new Chi biotechnology company) to extract protein (Ultrasound for $3 \mathrm{~s}, 2 \mathrm{~s}$ apart, lasting 99 times). The Bradford method was used to quantify the protein, and the integrity of the sample was checked by SDS-PAGE, then analyzed by LC-MS/MS $[56,57]$.

\section{Processing of TMT protein samples and LC-MS/MS analysis}

According to the instructions of manufacturer (Thermo Scientific), TMT reagent was used to label $100 \mu \mathrm{g}$ peptide mixtures of the samples respectively. The labeled peptides were separated using Thermo Scientific's High $\mathrm{pH}$ Reversed-Phase Peptide Separation Kit according to the instructions. Q Exactive mass spectrometer combined with Easy nLC (Thermo Scientific) for LC-MS/MS analysis. The samples were loaded onto a reversed-phase capture column (nanoViper C18, $100 \mu \mathrm{m} \times 2 \mathrm{~cm}$, Scientific Acclaim PepMap100) connected to a C18 reversedphase analytical column in $0.1 \%$ formic acid (buffer A), buffer B ( $0.1 \%$ formic acid and $84 \%$ acetonitrile) was used to separate with a linear gradient, $300 \mathrm{~nL} / \mathrm{min}$, positive ion mode. The MASCOT engine (Matrix Science, London, UK; version 2.2) embedded in the Proteome Discoverer 1.4 software was used to search the MS raw data of each sample for identification and quantitative analysis.

\section{Intracellular iron content detection}

The cell pellets of the wild-type and recombinant strains were collected after four days of cultivation and washed 3 times with PBS (10 mM, pH 7.8) at 10,000 rpm for $5 \mathrm{~min}$, and the supernatant was removed. Each tube of sample was added with $200 \mu \mathrm{L}$ of lysis buffer, incubated at $37^{\circ} \mathrm{C}$ for $2 \mathrm{~h}$, and then and then sonicated for $5 \mathrm{~min}$. The detection steps were performed in accordance with the instructions of the Intracellular Iron Colorimetric Assay Kit (Beijing Pulilai Gene Technology Co., Ltd.).

\section{Determination of intracellular acyl-CoA precursors}

The cell pellets of the wild-type and recombinant strains were collected after $2 \mathrm{~d}, 4 \mathrm{~d}$ and $6 \mathrm{~d}$ of cultivation, respectively. The freeze-thaw cycle was repeated to destroy the cell wall, then the supernatant was collected at $5000 \mathrm{rpm}$ for $8 \mathrm{~min}$, and the content of acetyl-CoA, malonyl-CoA and methylmalonyl-CoA were measured, respectively. The detection steps were performed in accordance with the instructions of the microorganism acetyl-CoA ELISA Kit, the microorganism malonyl-CoA ELISA Kit, and the microorganism methylmalonyl-CoA ELISA Kit (Shanghai FANKEL Industrial Co., Ltd.)

\section{Total antioxidant capacity (T-AOC) detection}

The cell pellets of the wild-type and recombinant strains were collected after four days of cultivation and washed 3 times with PBS (10 mM, pH 7.8) at 10,000 rpm for $5 \mathrm{~min}$. $1 \mathrm{~mL}$ pre-cooled extract was added to each tube sample, then, the cells were disrupted with ultrasound in an ice bath $(200 \mathrm{~W}$, ultrasonic $3 \mathrm{~s}$, interval $10 \mathrm{~s}$, repeat 30 times), centrifuged at $10,000 \mathrm{~g}$ for $5 \mathrm{~min}$ at $4{ }^{\circ} \mathrm{C}$, and placed on ice for testing. The detection steps were performed in accordance with the instructions of the Total Antioxidant Capacity Assay Kit (Beijing Boxbio Science \& Technology Co., Ltd.). 


\section{Strains resistance to $\mathrm{H}_{2} \mathrm{O}_{2}$ exposure}

$S$. pogona grew on CSM solid medium to produce white spores. The spore suspension of about $10^{10}$ spores/ $\mathrm{mL}$ was centrifuged at $5000 \mathrm{rpm}$ for $8 \mathrm{~min}$, and resuspended in $5 \mathrm{~mL}$ TES $(50 \mathrm{mM}, \mathrm{pH} 8.0)$. The spore suspension was heat shocked at $50{ }^{\circ} \mathrm{C}$ for $10 \mathrm{~min}$, quickly cooled to room temperature in cold water, and an equal volume of double-strength germination medium $\left(\mathrm{CaCl}_{2}\right.$ $1.11 \mathrm{~g} / \mathrm{L}$, casamino acid $10 \mathrm{~g} / \mathrm{L}$, yeast extract $10 \mathrm{~g} / \mathrm{L}$ ) was added. Then, the spore suspension was incubated with shaking at $37^{\circ} \mathrm{C}$ for $3 \mathrm{~h}$. The spore suspension was centrifuged at $4000 \mathrm{rpm}$ for $5 \mathrm{~min}$, the supernatant was removed. The spores were resuspended in water and fully dispersed, inoculated into $5 \mathrm{~mL}$ of CSM to $\mathrm{OD}_{450}$ of 0.05 , and cultured with shaking at $30{ }^{\circ} \mathrm{C}$ for $3 \mathrm{~h}$. Then, S. pogona cultures were treated with different concentrations of $\mathrm{H}_{2} \mathrm{O}_{2}$ at $30{ }^{\circ} \mathrm{C}$ for $30 \mathrm{~min}$. Finally, the cells were collected by centrifugation, diluted to a suitable gradient and plated on CSM agar for counting.

\section{Statistical analysis}

SPSS statistics version 19.0 was used to perform all the statistical analyses. $\mathrm{P}<0.05$ was considered statistically significant.

\begin{abstract}
Abbreviations
UHA: Upstream homology arm; DHA: Downstream homologous arm; Bfr: Bacterioferritin; SEM: Scanning electron microscopy; HPLC: High performance liquid chromatography; LC-MS/MS: Liquid chromatography mass spectrometry; DEPs: Differentially expressed proteins; T-AOC: Total antioxidant capacity; SFM: Synthetic fermentation medium; CSM: Complete synthetic medium.
\end{abstract}

\section{Supplementary Information}

The online version contains supplementary material available at https://doi. org/10.1186/s12934-021-01651-x.

Additional file 1: Table S1. Strains, plasmids and primers used in this study. Table S2. qRT-PCR primers used in this study. Table S3. Biological insecticidal activity of wt, $\triangle b f r$ and $:: b f r$. Figure S1. LC-MS/MS identification of butenyl-spinosyn. Figure S2. Phylogenetic tree analysis of bacterioferritin. Figure S3. Construction and recombination schematic diagram of pKCcas9dO-sgRNA-UHA-DHA and pOJ260-kasOp*-bfr. Figure S4. Identification of $\triangle b f r$ and $:: b f r$. Figure S5. Tricine-SDS-PAGE analysis and 1D-LCMS/MS identification of heterologously expressed protein Bfr. Figure $\mathbf{S 6}$. Butenyl-spinosyn yield curve of the wild-type and mutants. Figure S7. Statistics of total protein and differential protein between the wild-type and mutant strains identified in the quantitative proteome. Figure $\mathbf{S 8}$. The expression fold change of bus family proteins between bfr mutant strains and wild-type strain. Figure $\mathbf{S 9}$. Verification of the transcription levels of iron homeostasis and oxidative stress-related proteins.

Additional file 2: Table S4. DEPs in ::bfr.

Additional file 3: Table S5. DEPs in $\triangle b f r$.

Acknowledgements

Not applicable.

\section{Authors' contributions}

JT constructed the recombinant strains, performed phenotypic and the proteomics analysis, detected the concentrations of intracellular iron and acyl-COA. ZZ, HH and ZL performed the HPLC analysis and biological activity assay. ZX, JC and JH performed LC-MS/MS and T-AOC detection. LC and JR performed total RNA isolation and qRT-PCR analysis. LS, YL performed the analysis of strains resistance to $\mathrm{H}_{2} \mathrm{O}_{2}$ exposure. YS, XD, JT, SH and LX designed the experiments and wrote the manuscript. All authors read and approved the final manuscript.

\section{Funding}

This work was supported by funding from the National Natural Science Foundation of China (31770106), the Hunan Provincial Science and Technology Department (2019RS5001), and the Innovation Project and Professional Ability Enhancement Project of Postgraduate Education in Hunan Province (CX20200528)

\section{Availability of data and materials}

All data generated or analyzed during this study are included in this published article and its Additional files 1, 2, 3.

\section{Declarations}

\section{Ethics approval and consent to participate}

Ethical approval "All applicable international, national, and/or institutional guidelines for the care and use of animals were followed." All procedures performed in studies involving animals were in accordance with the ethical standards of the Animal Care Committee of Hunan Normal University at which the studies were conducted.

\section{Consent for publication \\ Not applicable.}

\section{Competing interests}

The authors declare that they have no competing interests.

Received: 29 April 2021 Accepted: 6 August 2021

Published online: 14 August 2021

\section{References}

1. Shen B. A new golden age of natural products drug discovery. Cell. 2015;163:1297-300

2. Gerwick BC, Sparks TC. Natural products for pest control: an analysis of their role, value and future. Pest Manag Sci. 2014;70:1169-85.

3. Sparks TC, Wessels FJ, Lorsbach BA, Nugent BM, Watson GB. The new age of insecticide discovery - the crop protection industry and the impact of natural products. Pestic Biochem Physiol. 2019;161:12-22.

4. Lewer P, Hahn DR, Karr LL, Duebelbeis DO, Gilbert JR, Crouse GD, Worden T, Sparks TC, Edwards PM, Graupner PR. Discovery of the butenyl-spinosyn insecticides: novel macrolides from the new bacterial strain Saccharopolyspora pogona. Bioorg Med Chem. 2009;17:4185-96.

5. Orr N, Shaffner AJ, Richey K, Crouse GD. Novel mode of action of spinosad: Receptor binding studies demonstrating lack of interaction with known insecticidal target sites. Pestic Biochem Physiol. 2009;95:1-5.

6. Araujo RDS, Lopes MP, Barbosa WF, Goncalves WG, Fernandes KM, Martins GF, Tavares MG. Spinosad-mediated effects on survival, overall group activity and the midgut of workers of Partamona helleri (Hymenoptera: Apidae). Ecotoxicol Environ Saf. 2019;175:148-54.

7. Sparks TC, Crouse GD, Benko Z, Demeter D, Giampietro NC, Lambert W, Brown AV. The spinosyns, spinosad, spinetoram, and synthetic spinosyn mimics-discovery, exploration, and evolution of a natural product chemistry and the impact of computational tools. Pest Manag Sci. 2020. https://doi.org/10.1002/ps.6073.

8. Rang J, He H, Yuan S, Tang J, Liu Z, Xia Z, Khan TA, Hu S, Yu Z, Hu Y, et al. Deciphering the metabolic pathway difference between Saccharopolyspora pogona and Saccharopolyspora spinosa by comparative proteomics and metabonomics. Front Microbiol. 2020;11:396. 
9. Liu Z, Zhu Z, Tang J, He H, Wan Q, Luo Y, Huang W, Yu Z, Hu Y, Ding X, Xia L. RNA-seq-based transcriptomic analysis of Saccharopolyspora spinosa revealed the critical function of PEP Phosphonomutase in the replenishment pathway. J Agric Food Chem. 2020;68:14660-9.

10. Dhakal D, Pokhrel AR, Jha AK, Thuan NH, Sohng JK. Saccharopolyspora species: laboratory maintenance and enhanced production of secondary metabolites. Curr Protoc Microbiol. 2017;44:10H.

11. Guojun Y, Yuping H, Yan J, Kaichun L, Haiyang X. A new medium for improving spinosad production by Saccharopolyspora spinosa. Jundishapur J Microbiol. 2016;9:e16765.

12. Tao H, Zhang Y, Deng Z, Liu T. Strategies for enhancing the yield of the potent insecticide spinosad in actinomycetes. Biotechnol J. 2019;14:e1700769.

13. Eustaquio AS, Chang LP, Steele GL, OD CJ, Koehn FE. Biosynthetic engineering and fermentation media development leads to gram-scale production of spliceostatin natural products in Burkholderia sp. Metab Eng. 2016;33:67-75

14. Waldron C, Matsushima P, Rosteck PR Jr, Broughton MC, Turner J, Madduri K, Crawford KP, Merlo DJ, Baltz RH. Cloning and analysis of the spinosad biosynthetic gene cluster of Saccharopolyspora spinosa. Chem Biol. 2001:8:487-99.

15. Hahn DR, Gustafson G, Waldron C, Bullard B, Jackson JD, Mitchell J. Butenyl-spinosyns, a natural example of genetic engineering of antibiotic biosynthetic genes. J Ind Microbiol Biotechnol. 2006;33:94-104.

16. Kirst HA. The spinosyn family of insecticides: realizing the potential of natural products research. J Antibiot. 2010;63:101-11.

17. Lu C, Zhang X, Jiang M, Bai L. Enhanced salinomycin production by adjusting the supply of polyketide extender units in Streptomyces albus. Metab Eng. 2016;35:129-37.

18. He H, Yuan S, Hu J, Chen J, Rang J, Tang J, Liu Z, Xia Z, Ding X, Hu S, Xia L. Effect of the TetR family transcriptional regulator Sp1418 on the global metabolic network of Saccharopolyspora pogona. Microb Cell Fact. 2020;19:27.

19. Rang J, Zhu Z, Li Y, Cao L, He H, Tang J, Hu J, Chen J, Hu S, Huang W, et al. Identification of a TetR family regulator and a polyketide synthase gene cluster involved in growth development and butenyl-spinosyn biosynthesis of Saccharopolyspora pogona. Appl Microbiol Biotechnol. 2021:105:1519-33.

20. Song C, Luan J, Li R, Jiang C, Hou Y, Cui Q, Cui T, Tan L, Ma Z, Tang YJ, et al. RedEx: a method for seamless DNA insertion and deletion in large multimodular polyketide synthase gene clusters. Nucleic Acids Res. 2020:48:e130

21. Rang J, He H, Chen J, Hu J, Tang J, Liu Z, Xia Z, Ding X, Zhang Y, Xia L. SenX3-RegX3, an important two-component system, regulates strain growth and butenyl-spinosyn biosynthesis in Saccharopolyspora pogona. iScience. 2020;23:101398.

22. Tala A, Damiano F, Gallo G, Pinatel E, Calcagnile M, Testini M, Fico D, Rizzo $D$, Sutera A, Renzone G, et al. Pirin: a novel redox-sensitive modulator of primary and secondary metabolism in Streptomyces. Metab Eng. 2018:48:254-68.

23. Jones SE, Pham CA, Zambri MP, McKillip J, Carlson EE, Elliot MA. Streptomyces volatile compounds influence exploration and microbial community dynamics by altering iron availability. mBio. 2019;10:e0171.

24. Andrews SC, Robinson AK, Rodriguez-Quinones F. Bacterial iron homeostasis. FEMS Microbiol Rev. 2003;27:215-37.

25. Andrews S, Norton I, Salunkhe AS, Goodluck H, Aly WS, Mourad-Agha $\mathrm{H}$, Cornelis P. Control of iron metabolism in bacteria. Met lons Life Sci. 2013;12:203-39.

26. Rivera M. Bacterioferritin: structure, dynamics, and protein-protein interactions at play in iron storage and mobilization. Acc Chem Res. 2017;50:331-40.

27. Honarmand Ebrahimi K, Hagedoorn PL, Hagen WR. Unity in the biochemistry of the iron-storage proteins ferritin and bacterioferritin. Chem Rev. 2015;115:295-326.

28. Pourciau C, Pannuri A, Potts A, Yakhnin H, Babitzke P, Romeo T. Regulation of iron storage by CsrA supports exponential growth of Escherichia coli. mBio. 2019;10:e01034.

29. Soldano $\mathrm{A}$, Yao H, Chandler JR, Rivera M. Inhibiting iron mobilization from bacterioferritin in Pseudomonas aeruginosa impairs biofilm formation irrespective of environmental iron availability. ACS Infect Dis. 2020;6:447-58.
30. Figueiredo MC, Lobo SA, Carita JN, Nobre LS, Saraiva LM. Bacterioferritin protects the anaerobe Desulfovibrio vulgaris Hildenborough against oxygen. Anaerobe. 2012;18:454-8.

31. Liu X, Qiu W, Rao B, Cao Y, Fang X, Yang J, Jiang G, Zhong Z, Zhu J. Bacterioferritin comigratory protein is important in hydrogen peroxide resistance, nodulation, and nitrogen fixation in Azorhizobium caulinodans. Arch Microbiol. 2019;201:823-31.

32. Yang J, Pan X, Xu Y, Li Y, Xu N, Huang Z, Ye J, Gao D, Guo M. Agrobacterium tumefaciens ferritins play an important role in full virulence through regulating iron homeostasis and oxidative stress survival. Mol Plant Pathol. 2020;21:1167-78.

33. Sharma $D$, Bisht $D$. Role of bacterioferritin and ferritin in $M$. tuberculosis pathogenesis and drug resistance: a future perspective by interactomic approach. Front Cell Infect Microbiol. 2017;7:240.

34. Eshelman K, Yao H, Punchi Hewage AND, Deay JJ, Chandler JR, Rivera $\mathrm{M}$. Inhibiting the BfrB: Bfd interaction in Pseudomonas aeruginosa causes irreversible iron accumulation in bacterioferritin and iron deficiency in the bacterial cytosol. Metallomics. 2017;9:646-59.

35. Llorente-Garcia I, Lenn T, Erhardt H, Harriman OL, Liu LN, Robson A, Chiu SW, Matthews S, Willis NJ, Bray CD, et al. Single-molecule in vivo imaging of bacterial respiratory complexes indicates delocalized oxidative phosphorylation. Biochim Biophys Acta. 2014;1837:811-24.

36. Koch-Koerfges A, Kabus A, Ochrombel I, Marin K, Bott M. Physiology and global gene expression of a Corynebacterium glutamicum Del$\operatorname{taF}(1) F(O)-A T P$ synthase mutant devoid of oxidative phosphorylation. Biochim Biophys Acta. 2012;1817:370-80.

37. Ren X, Liang F, He Z, Fan B, Zhang Z, Guo X, Du Y, Pang Y, Li J, Lyu J, Tan $G$. Identification of an intermediate form of ferredoxin that binds only iron suggests that conversion to holo-ferredoxin is independent of the ISC system in Escherichia coli. Appl Environ Microbiol. 2021;87:e03153.

38. Lu J, Holmgren A. The thioredoxin antioxidant system. Free Radic Biol Med. 2014;66:75-87.

39. Wan F, Feng X, Yin J, Gao H. Distinct H2O2-scavenging system in Yersinia pseudotuberculosis: KatG and AhpC act together to scavenge endogenous hydrogen peroxide. Front Microbiol. 2021;12:626874.

40. Kim HM, Shin JH, Cho YB, Roe JH. Inverse regulation of Fe- and Nicontaining SOD genes by a Fur family regulator Nur through small RNA processed from 3'UTR of the sodF mRNA. Nucleic Acids Res. 2014;42:2003-14.

41. Jiang L, Hu Z, Wang Y, Ru D, Li J, Fan J. Effect of trace elements on the development of co-cultured nitrite-dependent anaerobic methane oxidation and methanogenic bacteria consortium. Bioresour Technol. 2018;268:190-6.

42. Chen Y, Li F, Mao J, Chen Y, Nielsen J. Yeast optimizes metal utilization based on metabolic network and enzyme kinetics. Proc Natl Acad Sci USA. 2021. https://doi.org/10.1073/pnas.2020154118.

43. Cvetkovic A, Menon AL, Thorgersen MP, Scott JW, Poole FL 2nd, Jenney FE Jr, Lancaster WA, Praissman JL, Shanmukh S, Vaccaro BJ, et al. Microbial metalloproteomes are largely uncharacterized. Nature. 2010;466:779-82.

44. Ferousi C, Lindhoud S, Baymann F, Kartal B, Jetten MS, Reimann J. Iron assimilation and utilization in anaerobic ammonium oxidizing bacteria. Curr Opin Chem Biol. 2017:37:129-36.

45. Liu J, Chakraborty S, Hosseinzadeh P, Yu Y, Tian S, Petrik I, Bhagi A, Lu Y. Metalloproteins containing cytochrome, iron-sulfur, or copper redox centers. Chem Rev. 2014;114:4366-469.

46. Frawley ER, Fang FC. The ins and outs of bacterial iron metabolism. Mol Microbiol. 2014;93:609-16.

47. Bush MJ, Chandra G, Bibb MJ, Findlay KC, Buttner MJ. Genomewide chromatin immunoprecipitation sequencing analysis shows that WhiB is a transcription factor that cocontrols its regulon with WhiA to initiate developmental cell division in streptomyces. mBio. 2016;7:e00523-00516.

48. Molle V, Palframan WJ, Findlay KC, Buttner MJ. WhiD and WhiB, homologous proteins required for different stages of sporulation in Streptomyces coelicolor A3(2). J Bacteriol. 2000;182:1286-95.

49. Doukyu N, Taguchi K. Involvement of catalase and superoxide dismutase in hydrophobic organic solvent tolerance of Escherichia coli. AMB Express. 2021;11:97. 
50. Fischbach MA, Walsh CT. Assembly-line enzymology for polyketide and nonribosomal peptide antibiotics: logic, machinery, and mechanisms. Chem Rev. 2006;106:3468-96.

51. Huang $H$, Zheng G, Jiang W, Hu H, Lu Y. One-step high-efficiency CRISPR/ Cas9-mediated genome editing in Streptomyces. Acta Biochim Biophys Sin. 2015;47:231-43

52. Sander JD, Zaback P, Joung JK, Voytas DF, Dobbs D. Zinc Finger Targeter (ZiFiT): an engineered zinc finger/target site design tool. Nucleic Acids Res. 2007;35:W599-605

53. Li L, Rang J, He H, He S, Liu Z, Tang J, Xiao J, He L, Hu S, Yu Z, et al. Impact on strain growth and butenyl-spinosyn biosynthesis by overexpression of polynucleotide phosphorylase gene in Saccharopolyspora pogona. Appl Microbiol Biotechnol. 2018;102:8011-21.

54. Ma Z, Liu J, Lin X, Shentu X, Bian Y, Yu X. Formation, regeneration, and transformation of protoplasts of Streptomyces diastatochromogenes 1628. Folia Microbiol. 2014;59:93-7.
55. Yang Q, Ding X, Liu X, Liu S, Sun Y, Yu Z, Hu S, Rang J, He H, He L, Xia L. Differential proteomic profiling reveals regulatory proteins and novel links between primary metabolism and spinosad production in Saccharopolyspora spinosa. Microb Cell Fact. 2014;13:27.

56. Luo Y, Ding X, Xia L, Huang F, Li W, Huang S, Tang Y, Sun Y. Comparative proteomic analysis of Saccharopolyspora spinosa SP06081 and PR2 strains reveals the differentially expressed proteins correlated with the increase of spinosad yield. Proteome Sci. 2011;9:40.

57. Yang Q, Li Y, Yang H, Rang J, Tang S, He L, Li L, Ding X, Xia L. Proteomic insights into metabolic adaptation to deletion of metE in Saccharopolyspora spinosa. Appl Microbiol Biotechnol. 2015;99:8629-41.

\section{Publisher's Note}

Springer Nature remains neutral with regard to jurisdictional claims in published maps and institutional affiliations.
Ready to submit your research? Choose BMC and benefit from:

- fast, convenient online submission

- thorough peer review by experienced researchers in your field

- rapid publication on acceptance

- support for research data, including large and complex data types

- gold Open Access which fosters wider collaboration and increased citations

- maximum visibility for your research: over $100 \mathrm{M}$ website views per year

At BMC, research is always in progress.

Learn more biomedcentral.com/submissions 